\title{
ACOs and the 1\%: Changes in Spending Among High-Cost Patients Following the Medicare Shared Savings Program
}

\author{
Adam A. Markovitz, BS ${ }^{1,2}$, Samyukta Mullangi, MD MBA', \\ John M. Hollingsworth, MD MS ${ }^{1,3}$, Ushapoorna Nuliyalu, $M P H^{3}$, and Andrew M. Ryan, PhD',3
}

'University of Michigan Medical School, Ann Arbor, MI, USA; '² Department of Health Management \& Policy, University of Michigan School of Public Health, Ann Arbor, MI, USA; ${ }^{3}$ Institute for Healthcare Policy and Innovation, University of Michigan, Ann Arbor, MI, USA.

J Gen Intern Med 34(7):1116-8

DOI: $10.1007 / \mathrm{s} 11606-019-04963-2$

(c) Society of General Internal Medicine 2019

\section{INTRODUCTION}

Accountable Care Organizations (ACOs) were created by the Centers for Medicare and Medicaid Services (CMS) to improve efficiency and reduce unwarranted regional variations in spending. Because a small subset of high-cost patients drive total Medicare spending and may drive spending variation within and across regions, ${ }^{1}$ reducing spending among these patients is critical. Studies suggest the Medicare Shared Savings Program - CMS' flagship ACO program - is associated with modest spending decreases. ${ }^{2,3}$ However, it is unknown whether the MSSP has reduced spending for high-cost patients, and, if so, whether this has reduced regional spending variation. We asked two research questions: First, has the MSSP reduced spending for high-cost beneficiaries who potentially drive regional spending variation? Second, has the MSSP reduced spending variation within regions overall?

\section{METHODS}

Using national $100 \%$ data for Medicare fee-for-service beneficiaries in $2010(n=29,987,387)$ and $2014(n=30,848,623)$, we measured total spending per beneficiary at the 50th, 90th, and 99th spending percentiles for each region (hospital referral region). We adapted the Gini coefficient - typically used to summarize income inequality - to summarize spending variation within region. ${ }^{4}$ Gini coefficients range from 0 (if spending is equal across beneficiaries) to 1 (if spending is concentrated among one beneficiary). MSSP penetration was the proportion of beneficiaries in each region in the MSSP.

We performed first-differences analyses to test whether within-region changes in MSSP penetration were associated

This work was presented at the Society of General Internal Medicine Annual Meeting (April 2018) and the AcademyHealth Annual Research Meeting (June 2018).

Prior dissemination: This manuscript has not been previously published and is not under consideration in the same or substantially similar form in any other peer-reviewed media.

Published online May 7, 2019 with changes in spending at the 50th, 90th, and 99th percentiles and changes in each region's Gini coefficient. We con-

Table 1 Association Between Region-Level Medicare Shared Savings Program (MSSP) Penetration and Changes in Spending and Region-Level Variation (2010 and 2014)

\begin{tabular}{|c|c|c|c|c|c|}
\hline & $\begin{array}{l}\text { Mean } \\
\text { value } \\
\text { in } \\
\mathbf{2 0 1 0}^{\mathrm{d}}\end{array}$ & $\begin{array}{l}\text { Estimated } \\
\text { impact of } \\
\text { MSSP on } \\
\text { absolute } \\
\text { changes in } \\
\text { spending, } \\
\$(95 \% \\
\text { CI })^{b}\end{array}$ & $P^{\mathbf{e}}$ & $\begin{array}{l}\text { Estimated } \\
\text { impact of } \\
\text { MSSP on } \\
\text { relative } \\
\text { changes in } \\
\text { spending, } \\
\%(95 \% \\
\text { CI) }{ }^{\mathrm{b}, \mathrm{c}}\end{array}$ & $P^{\mathbf{e}}$ \\
\hline $\begin{array}{l}\text { Annual } \\
\text { spending } \\
\text { at } 50 \text { th } \\
\text { percentile }^{\mathrm{a}}\end{array}$ & $\$ 2183$ & $\begin{array}{l}-\$ 133 \\
(-\$ 224 \\
-\$ 43)\end{array}$ & 0.004 & $\begin{array}{l}-5.4 \\
(-9.1 \\
-1.8)\end{array}$ & 0.004 \\
\hline $\begin{array}{l}\text { Annual } \\
\text { spending } \\
\text { at 90th } \\
\text { percentile }^{\text {a }}\end{array}$ & $\$ 25,390$ & $\begin{array}{l}-\$ 1192 \\
(-\$ 2103 \\
-\$ 282)\end{array}$ & 0.010 & $\begin{array}{l}-4.6 \\
(-8.1 \\
-1.1)\end{array}$ & 0.010 \\
\hline $\begin{array}{l}\text { Annual } \\
\text { spending } \\
\text { at 99th } \\
\text { percentile }^{\text {a }}\end{array}$ & $\$ 95,535$ & $\begin{array}{l}-\$ 4602 \\
(-\$ 7416 \\
-\$ 1789)\end{array}$ & 0.001 & $\begin{array}{l}-4.9 \\
(-7.9 \\
-1.9)\end{array}$ & 0.001 \\
\hline $\begin{array}{l}\text { Gini } \\
\text { coefficient }\end{array}$ & 0.752 & $\begin{array}{l}0.002 \\
(-0.002 \\
0.006)\end{array}$ & 0.305 & $\begin{array}{l}0.3 \\
(-0.3,0.8)\end{array}$ & 0.304 \\
\hline
\end{tabular}

CI confidence interval, HRR hospital referral region, CMS Centers for Medicare \& Medicaid Services

${ }^{a}$ For each region (as defined by the 306 HRRs), we used: national 100\% data on cost and resource use for $2010(n=29,987,387)$ and $2014(n=$ 30,848,623) from the Medicare Beneficiary Annual Summary Files to define total Medicare spending; $100 \%$ data from CMS' Geographic Variation Public Use Files to define average beneficiary age, sex, racel ethnicity (white, black, Hispanic, other), Medicaid dual-eligibility, and comorbidity (CMS-Hierarchical Condition Category risk score); and a $20 \%$ random sample from the Shared Savings Program Beneficiary-Level File to define MSSP penetration. We excluded beneficiaries without 12 months of enrollment in Parts A and B of Traditional Medicare

${ }^{b}$ Homoskedastic standard errors were calculated after the BreuschPagan test failed to reject homoscedasticity

${ }^{c}$ Relative changes were calculated as the ratio of the absolute change in spending (or Gini coefficient) to the level of spending (or Gini coefficient) estimated for a "control" region, i.e., a region with 0\% MSSP penetration in the year 2014. For example, to estimate relative changes in spending for beneficiaries at the 50th percentile, we calculated the ratio of the estimated absolute change in spending (-\$133) to the estimated level of spending among beneficiaries in the 50th percentile in a region with 0\% MSSP penetration in 2014 (\$2447)

${ }^{d}$ Spending in 2010 was inflated to 2014 dollars using the Bureau of Labor Statistics Consumer Price Index (CPI) value of 1.0795 (https:// www.bls.gov/cpi/)

${ }^{e} P<0.05$ (two-sided) was considered statistically significant 
a

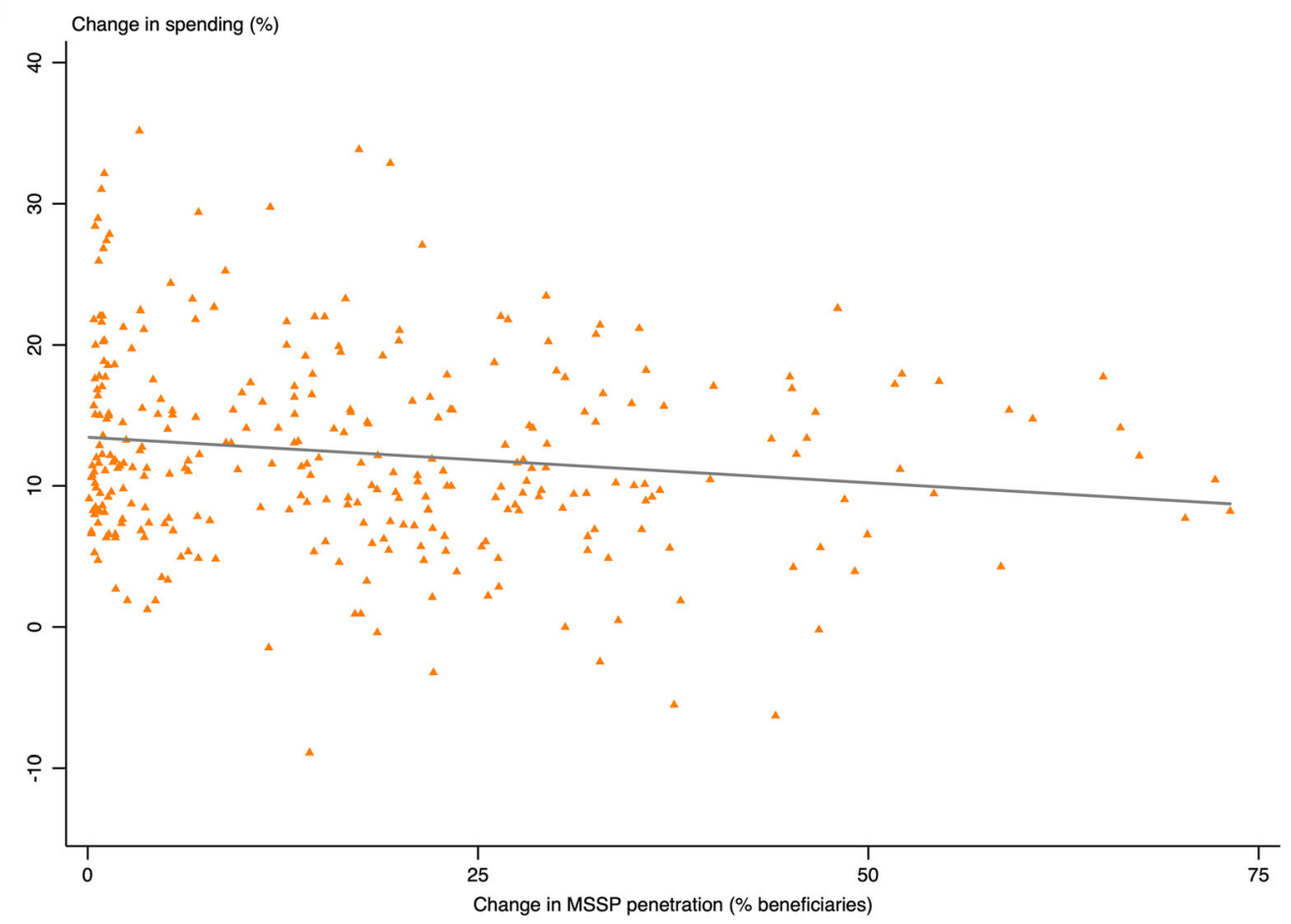

b

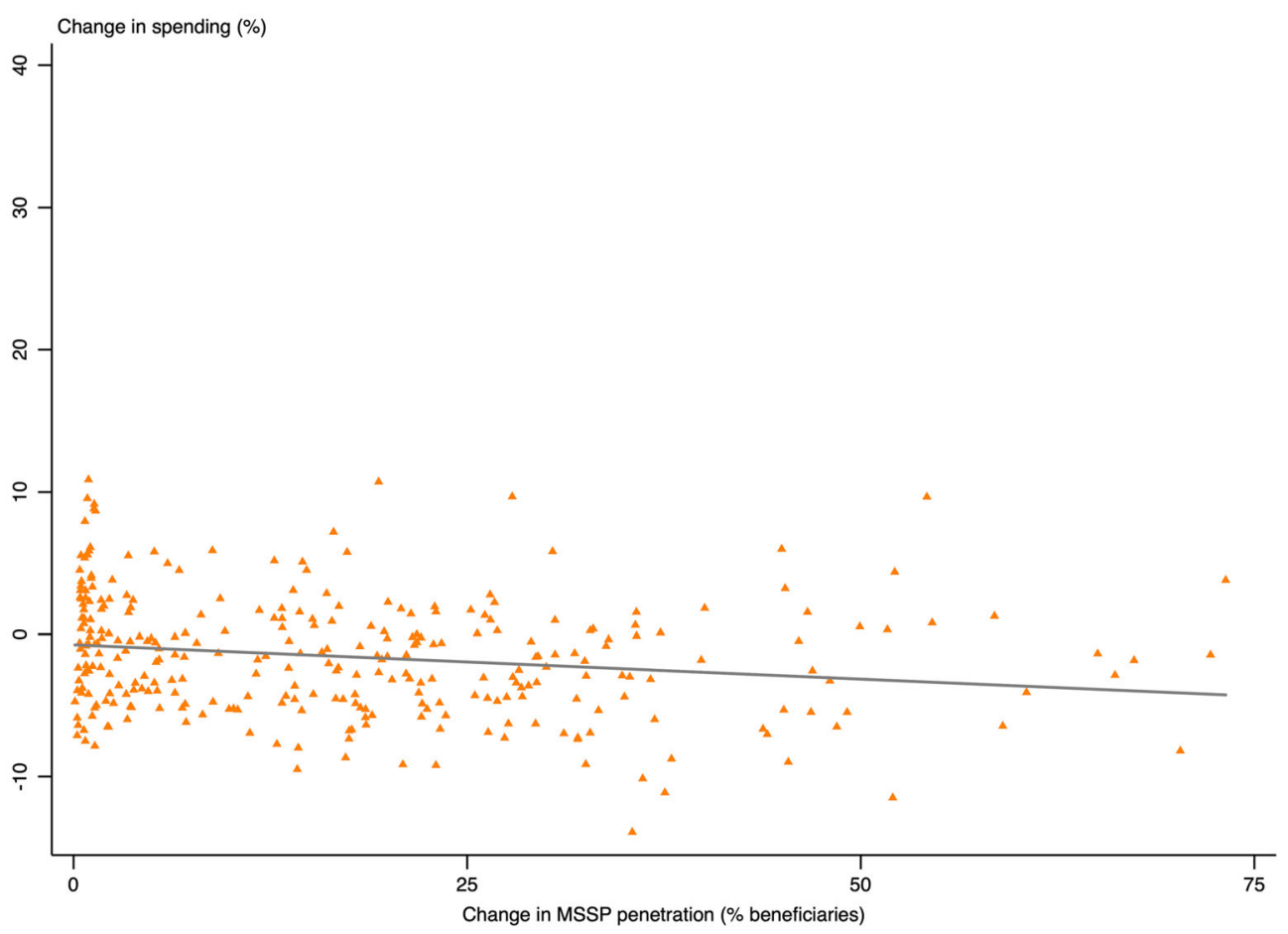

Figure 1 Region-level changes in spending and Medicare Shared Savings Program (MSSP) penetration between 2010 and 2014. In a and b, each orange triangle represents the percent change in average spending between 2010 and 2014 at a given percentile of spending for a given region. Percent changes were unadjusted and were calculated by dividing the region's absolute change in spending for a given percentile by the region's level of spending for a given percentile at baseline (2010). The gray line represents the fitted relationship between within-region change in MSSP penetration and within-region change in spending or the Gini coefficient, adjusting for year fixed effects and regional characteristics (listed in main text). 
trolled for fixed differences across regions, common shocks across years (year fixed effects), and regional changes in beneficiary age, sex, race, comorbidity, and Medicaid dualeligibility. This study was exempt from University of Michigan Institutional Review Board oversight.

\section{RESULTS}

High-cost beneficiaries drove spending variation within and across regions. For example, while spending for beneficiaries at the 50th percentile of spending differed by only $\$ 422$ between high- vs. low-spending regions (i.e., 75th vs. 25th percentile), this difference increased to $\$ 16,652$ for beneficiaries at the 99th percentile.

MSSP penetration was associated with consistent spending reductions overall (Table 1, Fig. 1). Changes in spending were uniform across moderate- vs. high-cost beneficiaries: a 1 percentage-point increase in MSSP penetration was associated with a spending change of $-5.4 \%$ among beneficiaries at the 50th percentile (95\% confidence interval $[\mathrm{CI}]-9.1 \%$, $1.8 \%) ;-4.6 \%$ at the 90 th percentile $(95 \%$ CI $-8.1 \%$, $1.1 \%$ ); and $-4.9 \%$ at the 99th percentile $(95 \% \mathrm{CI}-7.9 \%$,$1.9 \%)$. MSSP penetration was not associated with change in within-region spending variation (change in the Gini coefficient, 0.002; 95\% CI - 0.002, 0.006). However, MSSP penetration was associated with progressively greater absolute spending changes across the 50th $(-\$ 133)$, 90th $(-\$ 1192)$, and 99th $(-\$ 4602)$ percentiles.

\section{DISCUSSION}

Our study provides new evidence that the MSSP has not affected spending variation within or across regions. While the MSSP was associated with reduced spending overall, it was not associated with greater relative reductions among the high-cost beneficiaries who drive spending variation within and across regions. Our findings are consistent with prior evidence that MSSP ACOs achieved similar relative spending reductions among beneficiaries with high versus low medical complexity., ${ }^{5}$ The modest effect on high-cost beneficiaries may explain our finding that the MSSP has not reduced within-region spending variation.

As with prior MSSP evaluations, our study is limited by the program's voluntary nature. Regions with greater MSSP penetration may preferentially adopt other value-based initiatives. Our measure of MSSP penetration did not capture Pioneer or commercial ACOs. This ecological analysis could also miss underlying relationships between individual MSSP participation and spending. However, our savings estimate for median-spending beneficiaries ( $-\$ 133$ per year) is comparable to prior beneficiarylevel estimates for beneficiaries with mean levels of spending., ${ }^{2,3}$, ${ }^{5}$ Further, region-level analyses are necessary to evaluate changes in total variation and may capture spillover effects onto non-ACO beneficiaries. Finally, although high-cost beneficiaries typically have persistently high year-to-year spending, ${ }^{6}$ we did not follow a cohort of high-cost beneficiaries. Nonetheless, our study provides additional evidence that the MSSP has neither reduced spending variations within or across regions nor disproportionately reduced spending among high-cost beneficiaries. We hypothesize a number of design features in the MSSP, such as limited accountability for highest-cost patients (e.g., truncated spending at 99th percentile) and the absence of downside risk, may decrease incentives to focus on the highest-need patients.

Funding/Support: This work was supported by the Horowitz Foundation for Social Policy (AAM), AHRQ R36 HSO25615 (AAM), AHRQ RO1HSO24525 (JMH), RO1HSO24728 (JMH), and NIA RO1AG047932 (AMR).

Corresponding Author: Andrew M. Ryan, PhD; Department of Health Management \& Policy University of Michigan School of Public Health, Ann Arbor, MI, USA (e-mail: amryan@umich.edu).

Author Contribution All authors listed have contributed sufficiently to the project to be included as authors, and all those who are qualified to be authors are listed in the author byline.

Study concept and design: AAM, SM, JMH, AMR

Acquisition, analysis, or interpretation of data: all authors

Drafting of the manuscript: AAM, SM, and ARM

Critical revision of the manuscript for important intellectual content: all authors

Statistical analysis: AAM and UN

Obtained funding: JMH and AMR

Administrative, technical, or material support: JMH and AMR

\section{Compliance with Ethical Standards:}

This study was exempt from University of Michigan Institutional Review Board oversight.

Conflict of Interest: The authors declare that they do not have a conflict of interest.

Role of the Funder/Sponsor: The funding sources had no role in the design and conduct of the study; collection, management, analysis, and interpretation of the data; preparation, review, or approval of the manuscript; and decision to submit the manuscript for publication.

\section{REFERENCES}

1. Reschovsky JD, Hadley J, Saiontz-Martinez CB, Boukus ER. Following the Money: Factors Associated with the Cost of Treating High-Cost Medicare Beneficiaries. Health Serv Res. 46(4):997-1021. doi:https://doi. org/10.1111/j.1475-6773.2011.01242.x.

2. McWilliams JM, Hatfield LA, Chernew ME, Landon BE, Schwartz AL. Early Performance of Accountable Care Organizations in Medicare. N Engl $J$ Med. 2016;374(24):2357-2366. doi:https://doi.org/10.1056/ NEJMsa1600142.

3. Colla CH, Lewis VA, Kao L-S, O'Malley AJ, Chang C-H, Fisher ES. Association Between Medicare Accountable Care Organization Implementation and Spending Among Clinically Vulnerable Beneficiaries. JAMA Intern Med. 2016;176(8):1167-1175. doi:https://doi.org/10.1001/ jamainternmed.2016.2827.

4. Duoba V, MacGibbon N. Accurate Calculation of a Gini Index Using SAS and R. Wellington, New Zealand; 2017.

5. McWilliams JM, Chernew ME, Landon BE. Medicare ACO Program Savings Not Tied To Preventable Hospitalizations Or Concentrated Among High-Risk Patients. Health Aff. 2017;36(12):2085-2093. doi:https://doi. org/10.1377/hlthaff.2017.0814.

6. Riley GF. Long-Term Trends in the Concentration of Medicare Spending. Health Aff. 2007;26(3):808-816.

Publisher's Note: Springer Nature remains neutral with regard to jurisdictional claims in published maps and institutional affiliations. 